\title{
Efficacy of Incentive Spirometer Training on Diaphragmatic Excursion and Quality of Life in Hemodialysis Patients
}

\author{
HADEER S. MANSOUR, M.Sc.*; HALA M. EZZ EL-DEIN, Ph.D.*; FATMA A. MOHAMED, Ph.D.* and \\ TAREK F. AHMED, M.D.** \\ The Department of Physical Therapy for Internal Medicine, Faculty of Physical Therapy, Cairo University* and \\ The Department of Internal Medicine and Nephrology, National Institute of Urology and Nephrology**
}

\begin{abstract}
Background: The generalized muscle weakness found in Chronic Kidney Diseases (CKD) patients on hemodialysis primarily affects the lower limbs and the proximal muscles. Patients also present decreased endurance and decreased respiratory muscle strength.
\end{abstract}

Aim of Work: The purpose of this study was to evaluate the effect of incentive spirometer training on diaphragmatic excursion and Quality of Life (QOL) in Hemodialysis (HD) patients.

Subjects and Methods: Sixty HD patients (30 men and 30 women) selected from the National Institute of Urology and Nephrology participated in the study, their ages ranged from 45-55 years from July 2017 to January 2018. They were assigned randomly into two groups equal in number; 30 patients each: Group (A) received incentive spirometer training with hemodialysis for 8 weeks, 3 sessions per week. Group (B) maintained on hemodialysis only for 8 weeks 3 sessions per week with pre and post assessment of diaphragmatic excursion by ultrasonography and QOL questionnaire.

Results: Incentive spirometer training induced a significant improvement in diaphragmatic excursion and quality of life questionnaire in study group with percent of change $24.62 \%$ and $55.67 \%$ respectively while a deterioration was observed in control group with percent of change $26.49 \%$, and $38.68 \%$ respectively.

Conclusions: Incentive spirometer training for 8 weeks in HD men and women results in an improvement of diaphragmatic excursion and QOL.

Key Words: Hemodialysis - Incentive spirometer - Diaphragmatic excursion - Quality of life.

\section{Introduction}

CHRONIC Kidney Disease (CKD) is characterized by persisting renal damage and/or loss of renal function. The condition is associated with high

Correspondence to: Dr. Hadeer S. Mansour,

The Department of Physical Therapy for Internal Medicine, Faculty of Physical Therapy, Cairo University morbidity and mortality throughout the continuum from early disease to advanced stages that require renal replacement therapy. Although much progress has been made in prevention, detection and treatment, CKD remains a major public health problem. Its global prevalence is estimated at $5-10 \%$ and primarily because of cardiovascular morbidity and mortality, the global burden of CKD-associated diseases is alarmingly high [1]

Chronic kidney disease in fact, is not only a localized disease, but also affects virtually all organ systems, especially at the late stage of disease. Among these, respiratory system disorders are one of the most prevalent complications in ESRD patients [2].

In patients with End-Stage Renal Disease (ESRD), both kidney disease and hemodialysis treatment may severely affect the cardiorespiratory and musculoskeletal systems, contributing to a reduction in Functional Capacity (FC). Functional impairment adversely impacts patients' physical and mental capabilities and consequently, their ability to perform daily activities and maintain independence and social interactions [3].

Plasma proteins are severely excreted in the hemodialysis patients leading to muscle weakness and wasting affecting diaphragm. Significant muscle atrophy and associated weakness is seen in both dialysis patients and in patients with Chronic Kidney Disease (CKD) stages 3-4. This is associated with increased morbidity and mortality [4].

The impairment of uremia in the diaphragm have been studied by some authors who found; there is loss of diaphragm strength with severe uremia. The ventilatory deficit resulting from this compromise in the respiratory muscles, combined 
with other lung tissue compromises, contributing to decrease lung capacity [5]

The respiratory system is affected by kidney disease and HD treatment. Therefore, it is important to implement respiratory muscular training. A recent study showed that skeletal and respiratory physiotherapy can minimize the effects of uremic myopathy, and can improve pulmonary and muscular function and general clinical status. One of the factors that possibly contributed to the improvement of peripheral muscular strength was the implementation of combined respiratory and motor physiotherapy [6]

The specific training of respiratory muscles may be a useful alternative for patients with chronic kidney disease because the conditioning and strengthening of respiratory muscles can delay the complications of loss of muscle mass. Inspiratory muscle training may result in effects like phenotype modification of the respiratory muscles, increased respiratory muscle strength and endurance [7]

Incentive spirometers, also known as sustained maximal inspiration devices, are used to promote deep breathing. They measure the flow of air inhaled through the m outh piece and enhance pulmonary ventilation, overcome the effects of anesthesia or hypoventilation, loosen respiratory secretions, assist respiratory gaseous exchange, and help with re-expansion of collapsed alveoli. Incentive spirometer helps to avoid compromised inspiration and reduced tidal volume, which helps to prevent pneumonia. They are also valuable in providing patients with visual feedback of their respiratory effort [8]

Diaphragmatic exercises are used in order to augment diaphragmatic descent while inhalation and diaphragmatic ascent while expiration. The beneficial effects of diaphragmatic breathing are inflation of the alveoli, reversing postoperative hypoxemia, improvement of ventilation and oxygenation, decreasing the work of breathing, and increasing the degree of excursion of the diaphragm [9].

Patients receiving HD therapy have a low QOL, often accompanied by significant emotional distress characterized by symptoms of depression and anxiety. Depression is the most common mental disorder in HD patients [10].

Therefore, the purpose of this study was to investigate the effect of Incentive Spirometer (IS) on diaphragmatic excursion and quality of life in patients on hemodialysis.

\section{Material and Methods}

Sixty patients of both sexes (30 men and 30 women) with chronic kidney disease who underwent hemodialysis for (3-5 years) were included in the study, aged from 45-55 years old and were selected from Hemodialysis Unit at The National Institute of Urology and Nephrology. The training program was carried in the duration from July 2017 to January 2018. They were referred from the physician and assigned randomly into two groups equally in number: Group (A): Study Group with 30 patients who received incentive spirometer training ( 3 sessions per week) plus traditional medical treatment (Medications and Hemodialysis). Group (B): Control group with 30 patients who maintained on traditional medical treatment only (Medications and Hemodialysis). The study was approved by Research Ethical Committee of Faculty of Physical Therapy, Cairo University and a written informed consent was signed by each patient.

All patients were subjected to full clinical history and full clinical examination and any patient with any of the following was excluded: Instability of patient's medical condition, patients with chest infection, inability to comprehend and follow instructions as in dementia or speech problems such as dysphasia, uncontrolled diabetes mellitus, persistent systolic Blood Pressure (BP) greater than $200 \mathrm{mmHg}$, persistent diastolic BP greater than $120 \mathrm{mmHg}$, chronic lung disease which result in significant oxygen desaturation on exercise or pulmonary congestion and patients with lupus nephritis.

Also any patient who missed more than two weeks of the program or want to terminate the program was excluded.

\section{A- Evaluative equipments:}

1- Ultrasonography (Aloka prosound 4000, made in Japan) that was used to assess diaphragmatic excursion.

2- The Short-Form Health Survey (SF-36) Questionnaire to assess quality of life.

The assessment of diaphragmatic excursion and quality of life were performed before and after the training program in patients in the study group and 8 weeks apart in patients in control group.

\section{B- Treatment equipment:}

Triflow device flow-oriented incentive spirometer (made in India). 


\section{Treatment procedure:}

The group (A): Study group:

Patients in the study group received training with incentive spirometer in addition to their medical treatment and hemodialysis. The training was during hemodialysis session and a full explanation of treatment procedures was given to the patients.

Dialysis session lasts for four hours and the training began during the third hour.

Training by using incentive spirometer [11]:

- Loosen any tight clothing, especially around neck.

- Each patient was instructed to sit upright with placing incentive spirometer at the same level of his mouth to promote optimal lung expansion while using the spirometer.

- The patient was instructed to exhale letting all the breath out.

- Ask the patient to close the lips around the mouthpiece of the spirometer.

- Instruct the patient to inhale slowly, breathing in until unable to do any more, this would raise the balls to the top of the column.

- Ask the patient to hold the breath as long as possible (at least five seconds) then exhale slowly.

- Session was in the form of 30 times in sets, each set consist of 5-6 repititions with rest 1 minute between sets.

- Intensity of exercise was increased by increasing time of session, time of holding the breath and numbers of repititions according to patient's status.

- The training was 3 times/week for 8 weeks.

- The group (B): Control group: Patients in this group were maintained on their medical treatment and hemodialysis.

\section{Statistical analysis:}

Descriptive statistics and $t$-test were conducted for comparison of the mean of age between both groups. Unpaired $t$-test was conducted for compar- ison of pre and post-treatment mean values of DE and SF-36 between groups and paired $t$-test was conducted for comparison between pre and posttreatment mean values of DE and SF-36 within each group. The level of significance for all statistical tests was set at $p \leq 0.05$. All statistical measures were performed through the Statistical Package for Social Studies (SPSS) Version 19 for windows.

\section{Results}

\section{Subjects characteristics:}

The comparison between both groups regarding the age revealed a non statistical significant difference $(p<0.05)$. While the sex distribution in both groups was $50 \%$ females, $50 \%$ males as shown in (Table 1).

\section{Analysis of the diaphragmatic excursion:}

Analysis of the results showed that there was a significant increase in DE in the study group from pre to post-treatment measurement with $p>0.05$ while in the control group the DE showed significant decrease at the end of the study with $p>0.05$. Comparison of DE between both groups at pre-treatment measurement showed non statistical significant difference $(p<0.05)$ which changed into a high statistical significant difference at the end of the study $(p>0.05)$ in favor of the study group (Table 2).

\section{Analysis of QOL results (general health domain):}

Comparison of QOL score (GH domain) between pre \& post-treatment measurements within study group showed significant increase in the score with $p>0.05$ and percent of improvement of $57.14 \%$ while in the control group the QOL score (GH domain) showed significant reduction with $p$ $>0.05$ and percent of reduction of $30 \%$ as shown in (Table 3).

There was non-significant difference between both groups regarding QOL score (GH domain) at pre-treatment while at post-treatment measurement the QOL score (GH domain) significantly increase in the study group as shown in (Table 3 ).

Table (1): Subjects characteristics.

\begin{tabular}{|c|c|c|c|c|}
\hline & Study group & Control group & $p$-value & Sig. \\
\hline Age $(X \pm S D)$ years & $52.26 \pm 4.75$ & $52.86 \pm 4.28$ & 0.6 & NS \\
\hline $\operatorname{Sex}(M / F)$ No. & $15 / 15$ & $15 / 15$ & & \\
\hline $\begin{array}{l}X: \text { Mean. } \\
\text { SD : Standard Deviation. } \\
M \text { : Male. }\end{array}$ & & $\begin{array}{l}\text { : Female. } \\
\text { lue : Probability } \\
\text { : Non Signific }\end{array}$ & & \\
\hline
\end{tabular}


Table (2): Comparison of DE between both groups \& within each group.

\begin{tabular}{|c|c|c|c|c|c|}
\hline & $\begin{array}{l}\text { Pre-treatment } \\
(\overline{\mathrm{X}} \pm \mathrm{SD})\end{array}$ & $\begin{array}{l}\text { Post-treatment } \\
\quad(\mathrm{X} \pm \mathrm{SD})\end{array}$ & $\begin{array}{l}\% \text { of } \\
\text { change }\end{array}$ & $p$-value & Significance \\
\hline Study group & $5.28 \pm 1.91$ & $6.58 \pm 1.96$ & $24.62(\uparrow)$ & 0.0001 & S \\
\hline Control group & $5.7 \pm 1.79$ & $4.19 \pm 1.56$ & $26.49(\downarrow)$ & 0.0001 & S \\
\hline$b$-value & 0.37 & 0.0001 & & & \\
\hline Significance & NS & S & & & \\
\hline $\begin{array}{ll}\mathrm{x} & : \text { Mean. } \\
\text { NS } & : \text { Non-Si } \\
b \text {-value } & \text { Probab }\end{array}$ & $\begin{array}{l}\text { cant. } \\
\text { value. }\end{array}$ & $\begin{array}{l}\text { SD : } \\
\text { S : }\end{array}$ & $\begin{array}{l}\text { andard devi } \\
\text { gnificant. }\end{array}$ & & \\
\hline
\end{tabular}

Table (3): Comparison of QOL (GH domain) between both groups and within each group.

\begin{tabular}{|c|c|c|c|c|c|}
\hline & $\begin{array}{l}\text { Pretreatment } \\
(\overline{\mathbf{X}} \pm \mathbf{S D})\end{array}$ & 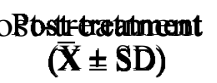 & $\begin{array}{c}\% \text { of } \\
\text { change }\end{array}$ & p-value & Significance \\
\hline $\begin{array}{l}\text { Study group } \\
\text { Control group } \\
p \text {-value } \\
\text { Significance }\end{array}$ & $\begin{array}{l}215.83 \pm 43.29 \\
225 \pm 51.69 \\
0.46 \\
\text { NS }\end{array}$ & $\begin{array}{l}339.16 \pm 74.18 \\
157.5 \pm 37.8 \\
0.0001 \\
S\end{array}$ & $\begin{array}{l}57.14(\uparrow) \\
30(\downarrow)\end{array}$ & $\begin{array}{l}0.0001 \\
0.0001\end{array}$ & $\begin{array}{l}S \\
S\end{array}$ \\
\hline $\begin{array}{ll}\mathrm{X} & : \text { Mean. } \\
\mathrm{NS} & : \text { Non-Si } \\
p \text {-value }: \text { Probabi }\end{array}$ & $\begin{array}{l}\text { cant. } \\
\text { value. }\end{array}$ & $\begin{array}{l}\text { SD : } \\
S:\end{array}$ & $\begin{array}{l}\text { andard dev } \\
\text { gnificant. }\end{array}$ & & \\
\hline
\end{tabular}

\section{Discussion}

This study was conducted to assess the responses of diaphragmatic excursion and quality of life to incentive spirometer training in hemodialysis patients in both genders.

Results of this study showed clearly that incentive spirometer training for 8 weeks; have significant positive effects on diaphragmatic excursion and quality of life in CKD patients on hemodialysis. This improvement in diaphragmatic excursion may be due to improvement of diaphragm mechanics, power and strength of inspiratory muscles.

During the current study M-mode Ultrasonography was used for assessment of diaphragmatic excursion which was approved as an accepted method for assessment of diaphragmatic motion in normal and pathological conditions [12]

Incentive Spirometer training promotes greater diaphragmatic excursion assessed by ultrasonography in healthy subjects during rest and different types of breathing exercises [13].

The results of this study came in accordance with Reda et al., [14] who stated that inspiratory muscle training had a significant effect on diaphragmatic excursion in patients who were subjected to open heart surgery. Also it helped to improve the inspiratory muscle function, exercise capacity and reduce breathlessness.

Zayed et al., [15] stated that I.S maneuver resulted in significant increase in D.E during deep breathing after elective upper abdominal surgeries. Also D.E contributed mainly to deep breathing maneuver through I.S post-operatively.

De Medeiros et al., [16] stated that inspiratory muscle training improves maximal respiratory pressures, lung function, functional capacity and quality of life in patients with chronic renal failure who are receiving hemodialysis.

The result of our study are consistent with the results of Ahmed et al., [17] who found that the I.S maneuver resulted in significant increase in D.E during deep breathing and it enhance the D.E.

Studies in COPD done by Smart et al., [18] showed that, in addition to increasing respiratory muscle strength, inspiratory muscle training improved functional capacity, exercise capacity, dyspnea and quality of life.

On the other hand the results of the current study contradict the results of Barbalho-Moulim et al., [19] who reported a non-significant change in Diaphragmatic Excursion (DE) with inspiratory muscle training program for 4 weeks but the difference might be explained by short duration of the study.

\section{Conclusion:}

The results of this study support the importance of inspiratory muscle training program on hemodialysis patients in the form of incentive spirometer training 3 times per week which able to safely improve their diaphragmatic excursion and improve 
capacity for independent living and enhanced quality of life.

\section{References}

1- DELLES C. and VANHOLDER R.: Chronic kidney disease; Clin. Sci. (Lond), 1; 131 (3): 225-6, 2017.

2- REZAEETALAB F., ZERAATI A., FADAEIAN A., AKBARIRAD M., AZAMI G., LARI S. and ASNAASHARI A.: Spirometric parameters: Hemodialysis compared to peritoneal dialysis. J. Cardiothorac. Med., 3 (2): 293-96, 2015.

3- FASSBINDER T.R., WINKELMANN E.R., SCHNEIDER J., WENDLAND J. and OLIVEIRA O.B.: Functional Capacity and Quality of Life in Patients With Chronic Kidney Disease in Pre-Dialytic Treatment and on Hemodialysis-A Cross sectional study. J. Bras. Nefrol., 37 (1): 47-54, 2015.

4- JOHN S.G., SIGRIST M.K., TAAL M.W. and McINTYRE C.W.: Natural History of Skeletal Muscle Mass Changes in Chronic Kidney Disease Stage 4 and 5 Patients: An Observational Study. PLoS ONE, 8 (5): e65372, 2013.

5- DIPP T., SILVA A., SIGNORI L., STRIMBAN T., NICOLODI G., SBRUZZI G., MOREIRA P. and PLENTZ R.: Respiratory muscle strength and functional capacity in end-stage renal disease (ESRD). Rev. Bras. Med. Esporte, 16 (4): 246-49, 2010.

6- NETO J.R., FIGUEIREDO E. CASTRO L.M., SANTOS De OLIVEIRA F., SILVA A.M., MARIA DOS REIS L., QUIRINO A.P., DRAGOSAVAC D. and KOSOUR C. Comparison between two physiotherapy protocols for patients with chronic kidney disease on dialysis. J. Phys. Ther. Sci., 28 (5): 1644-50, 2016.

7- FIGUEIREDO R.R., CASTRO A.A., NAPOLEONE F.M., FARAY L., De PAULA JÚNIOR A.R. and OSÓRIO R.A.: Respiratory biofeedback accuracy in chronic renal failure patients: A method comparison Clin. Rehabil., 26 (8): 724-32, 2012.

8- BERMAN A.: Kozier and Erb's Fundamentals: Concepts, process and Practice. Boston, MA: Pearson Education, Inc (p86, 145), 2012.

9- GRAMS S., ONO L., NORONHA M., SCHIVINSKI C. and PAULIN E.: Breathing exercises in upper abdominal surgery: A systematic review and meta-analysis. Brazilian Journal of Physical Therapy, 16 (5): 345-53, 2012.

10- BAGGETTA R., BOLIGNANO D., TORINO C., MANFREDINI F., AUCELLA F., BARILLÀ A., BATTAGLIA Y., BERTOLI S., BONANNO G. and CASTELLINO P.:
Fitness for Entering a Simple Exercise Program and Mortality: A Study Corollary to the Exercise Introduction to Enhance Performance in Dialysis (Excite) Trial. Kidney Blood Press Res., 39 (2-3): 205-11, 2014.

11- RESTREPO R., WETTSTEIN R., WITTNEBEL L. and TRACY M.: Clinical Practice Guidelines. Incentive spirometry. Respiratory Care. 2, 56 (10): 1600-4, 2011.

12- KIM S.H., NA S., CHOI J.S., NA S.H., SHIN S. and KOH S.O.: An evaluation of diaphragmatic movement by M-mode sonography as a predictor of pulmonary dysfunction after upper abdominal surgery. Anesth. Analg., 110 (5): 1349-54, 2010.

13- UDAYAMALA E., ALAPARTHI G.K., AUGUSTINE A.J., ANAND R., MAHALE A., ZULFEEQUER C.P. and SHYAM KRISHNAN K.: Comparison of Diaphragmatic Excursion During Diaphragmatic Breathing Exercise, Volume and Flow Oriented Incentive Spirometer in Healthy Subjects: A Randomized Cross Over Trial. Online J. Health Allied Scs., 15 (3): 7, 2016.

14- REDA I., MOHAMED Z., HASSAN S. and SABRY A.: Effect of inspiratory muscle training on diaphragmatic Excursion after valvular surgery, Master Thesis, Faculty of Physical Therpy, Cairo University. No. 2300, 2010.

15- ZAYED E., AHMED M. and SALEM E.: Impact of Incentive Spirometry on Diaphragmatic Excursion in upper abdominal surgeries. International Journal of Scientific Research and Management, 5 (08): 2321-3418, 2015.

16- De MEDEIROS A.I.C., FUZARI H.K.B., RATTESA C., BRANDÃO D.C. and De MELO MARINHO P.É.: Inspiratory muscle training improves respiratory muscle strength, functional capacity and quality of life in patients with chronic kidney disease: A systematic review. J. Physiother. 63 (2): 76-83, 2017.

17- AHMED H., HELMY Z. and ABD-ELGHANY A.: Effect of incentive spirometer on diaphragmatic excursion after mitral valve replacement, Master Thesis, Faculty of Physical Therapy, Cairo University, No. 2351, 2011.

18-SMART N., GIALLAURIA F. and DIEBERG G.: Efficacy of inspiratory muscle training in chronic heart failure patients: A systematic review and meta-analysis. Int. J. Cardiol., 167: 1502-7, 2013.

19- BARBALHO-MOULIM M.C., MIGUEL G.P., FORTI E.M., CAMPOS FDO A. and COSTA D.: Effects of preoperative inspiratory muscle training in obese women undergoing open bariatric surgery: Respiratory muscle strength, lung volumes, and diaphragmatic excursion. Clinics (Sao Paulo), 66 (10): 1721-7, 2011. 


\section{تآثير التدريب بجهاز الحافز التنفسى على إزاحة الحجاب الحاجز الحزي

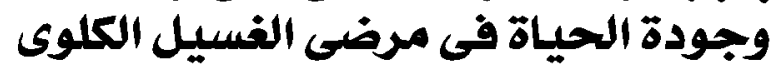

الغسيل الكلوى ينتج عنه الكثير من المشاكل الصحية ومنها ضعف العضلات وآهمها عضلات التفس خاصة عضلة الحجاب الحاجز وقد

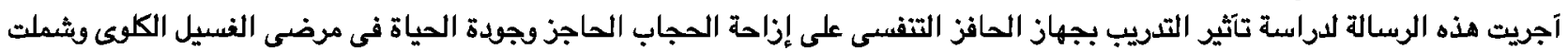

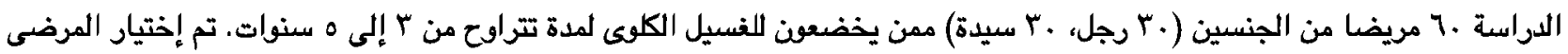

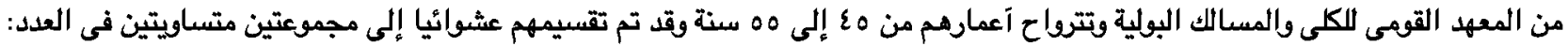

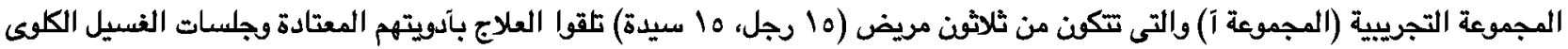

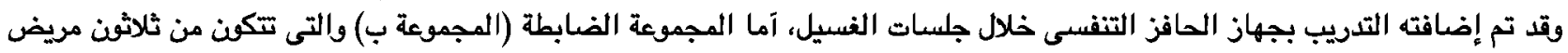

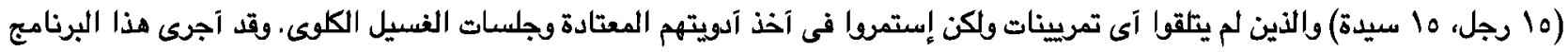

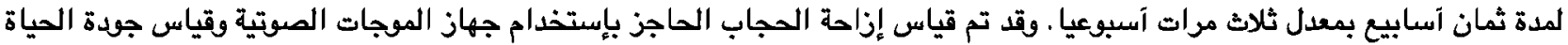

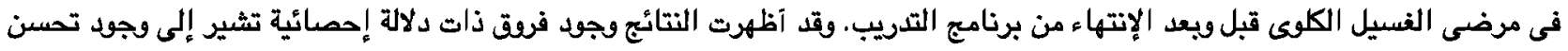

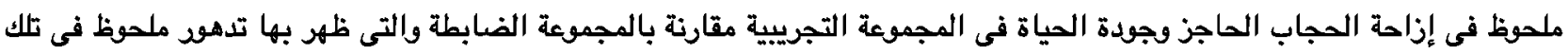

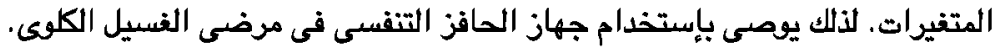

